Supporting Information for

\title{
One-Step Trimethylstannylation of Benzyl and Alkyl Halides
}

Jianbing Jiang, Robert H. Crabtree* and Gary W. Brudvig*

Department of Chemistry, Yale University, New Haven, Connecticut 06520, USA and Energy Sciences Institute, Yale University, West Haven, Connecticut 06516, USA

*Corresponding Authors:

robert.crabtree@yale.edu

gary.brudvig@yale.edu

NMR Spectra of Compounds 1-4, 7-13 and 17-19

pages $\mathrm{S} 2-\mathrm{S} 14$ 

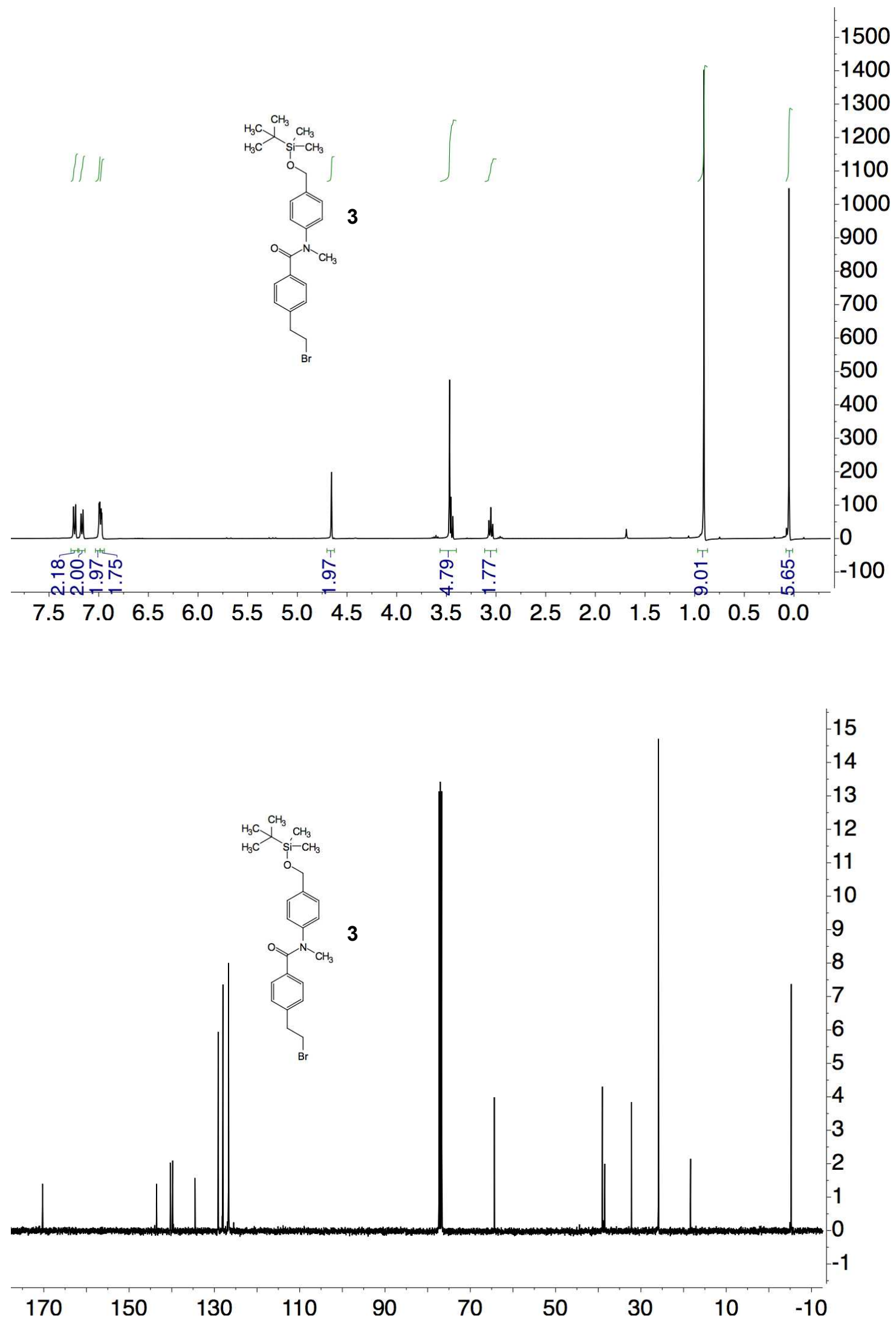

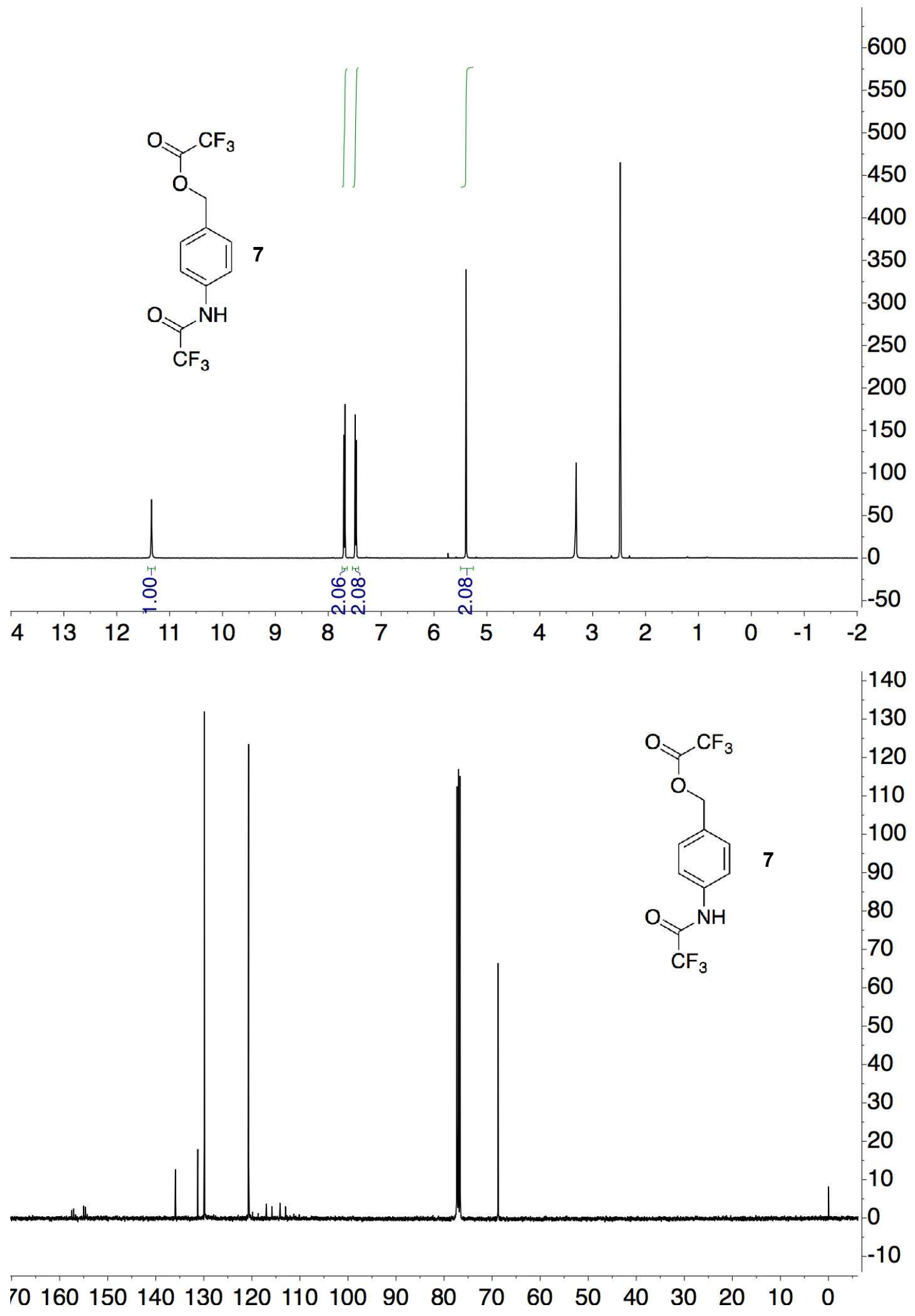

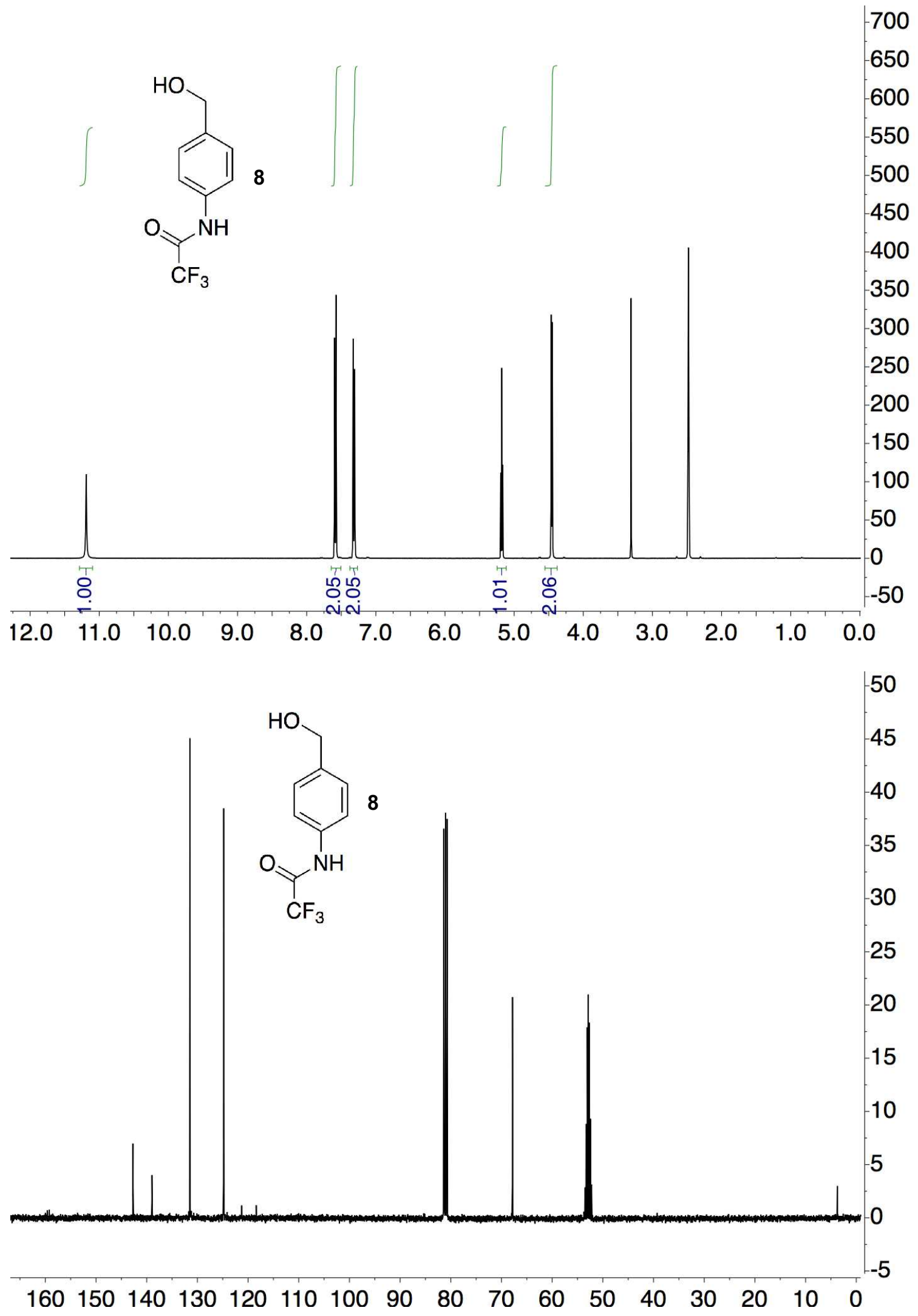


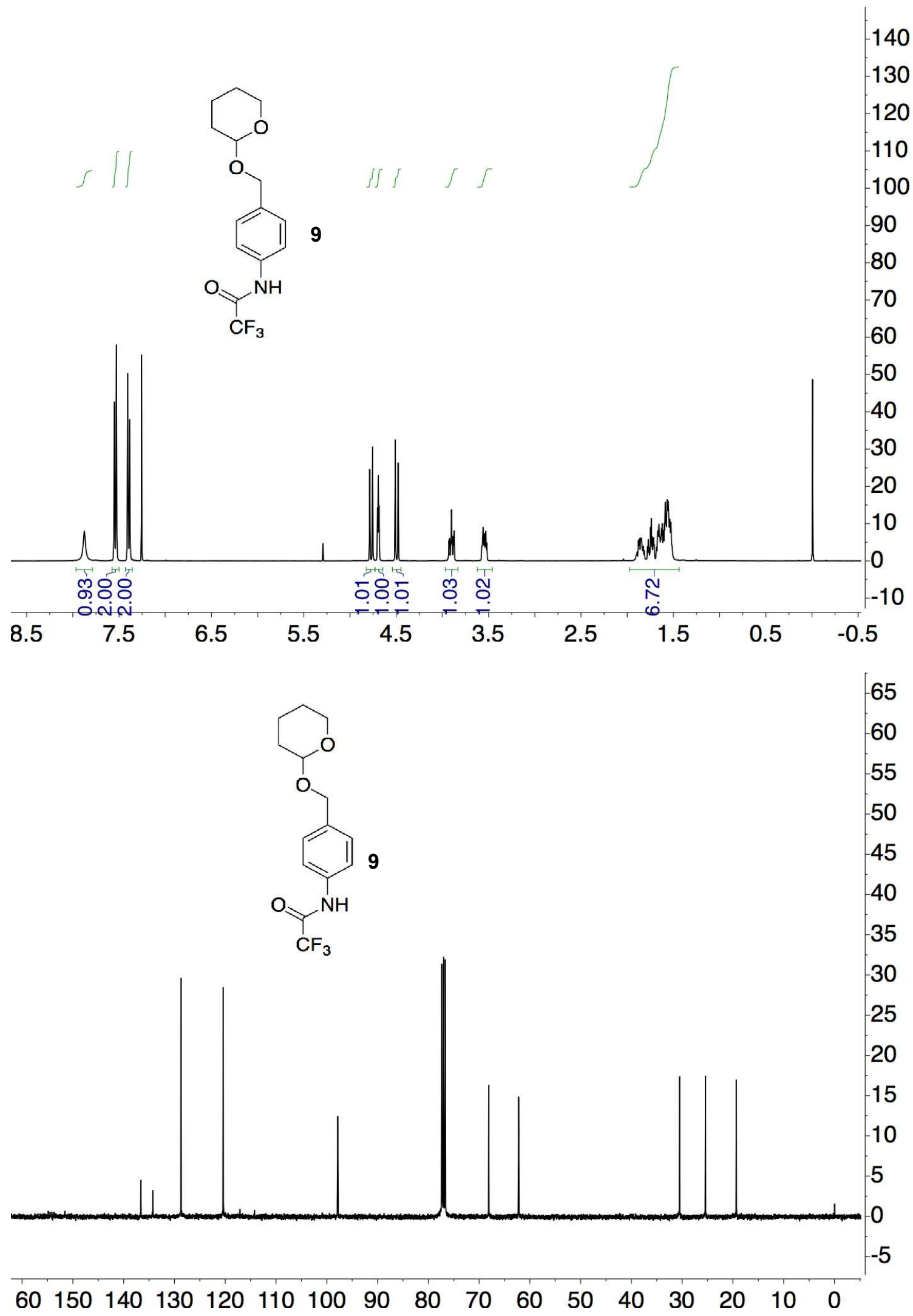



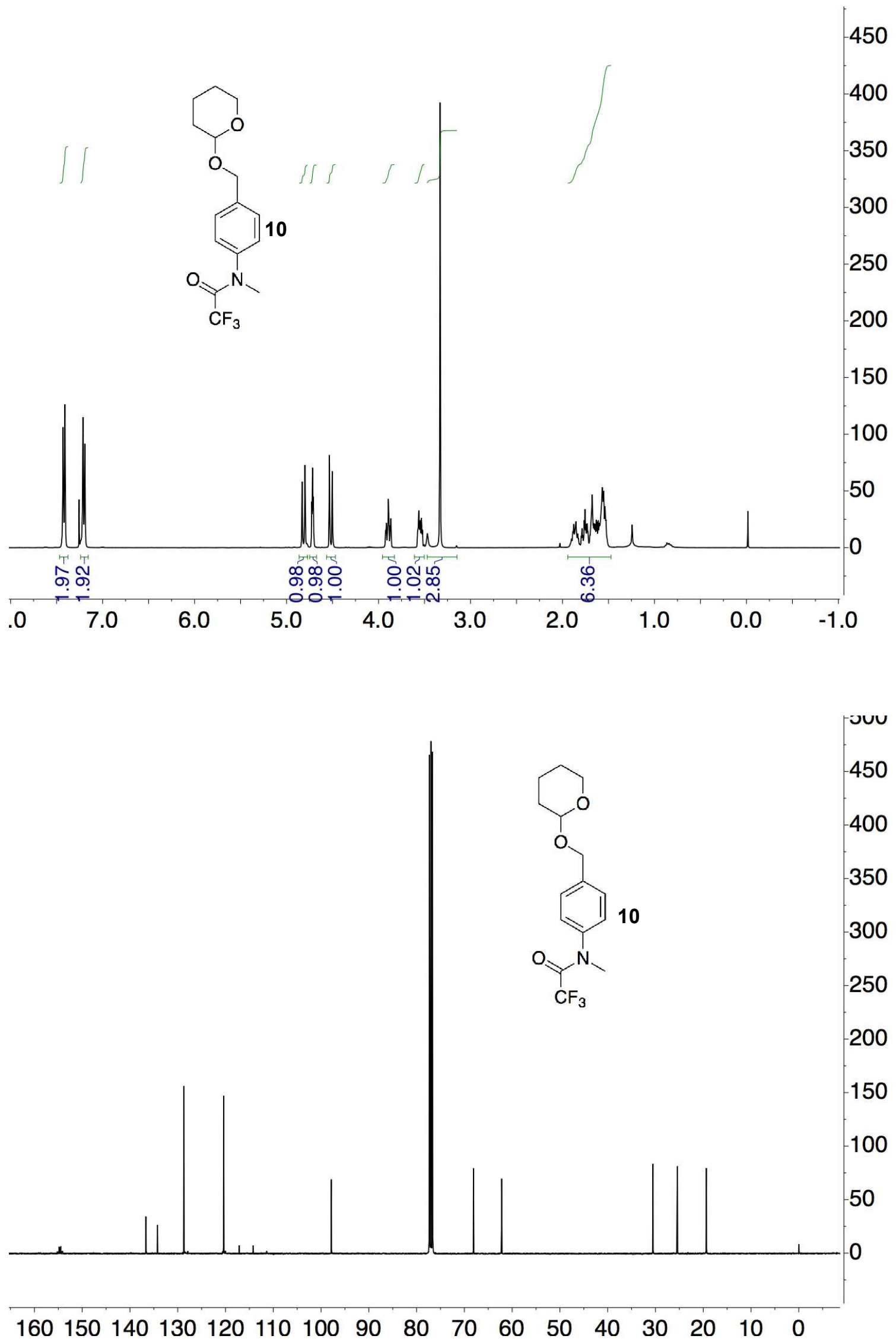

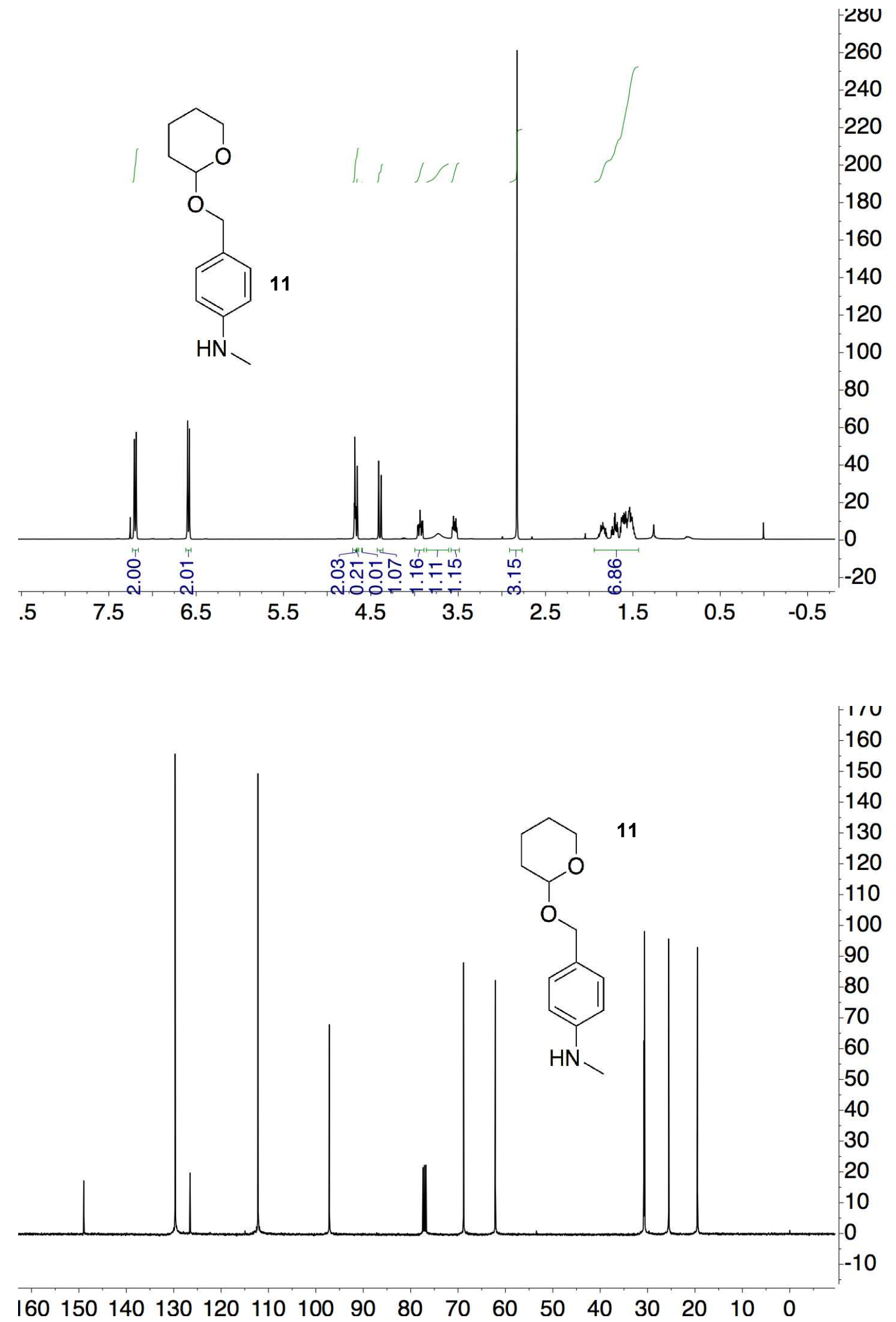

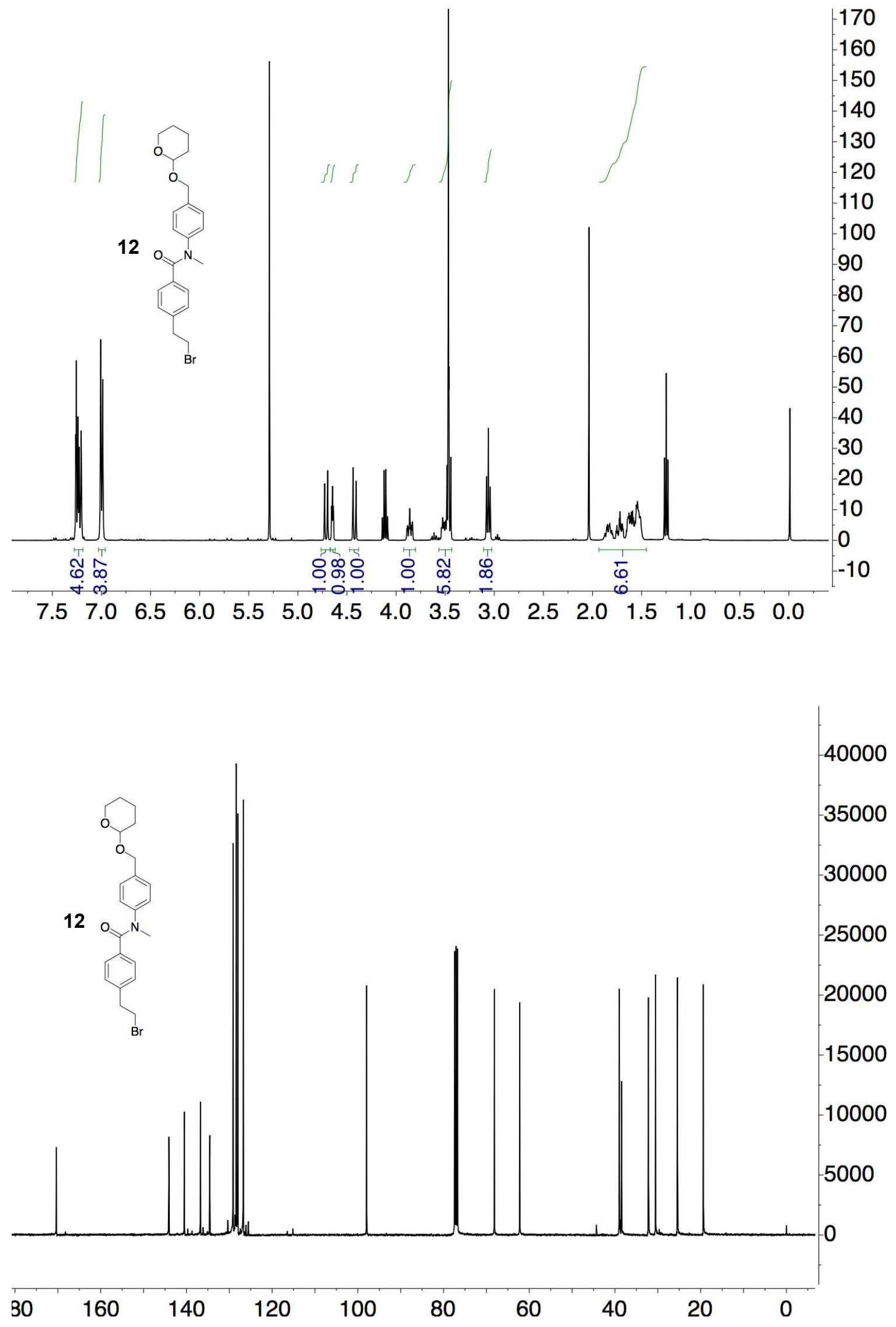

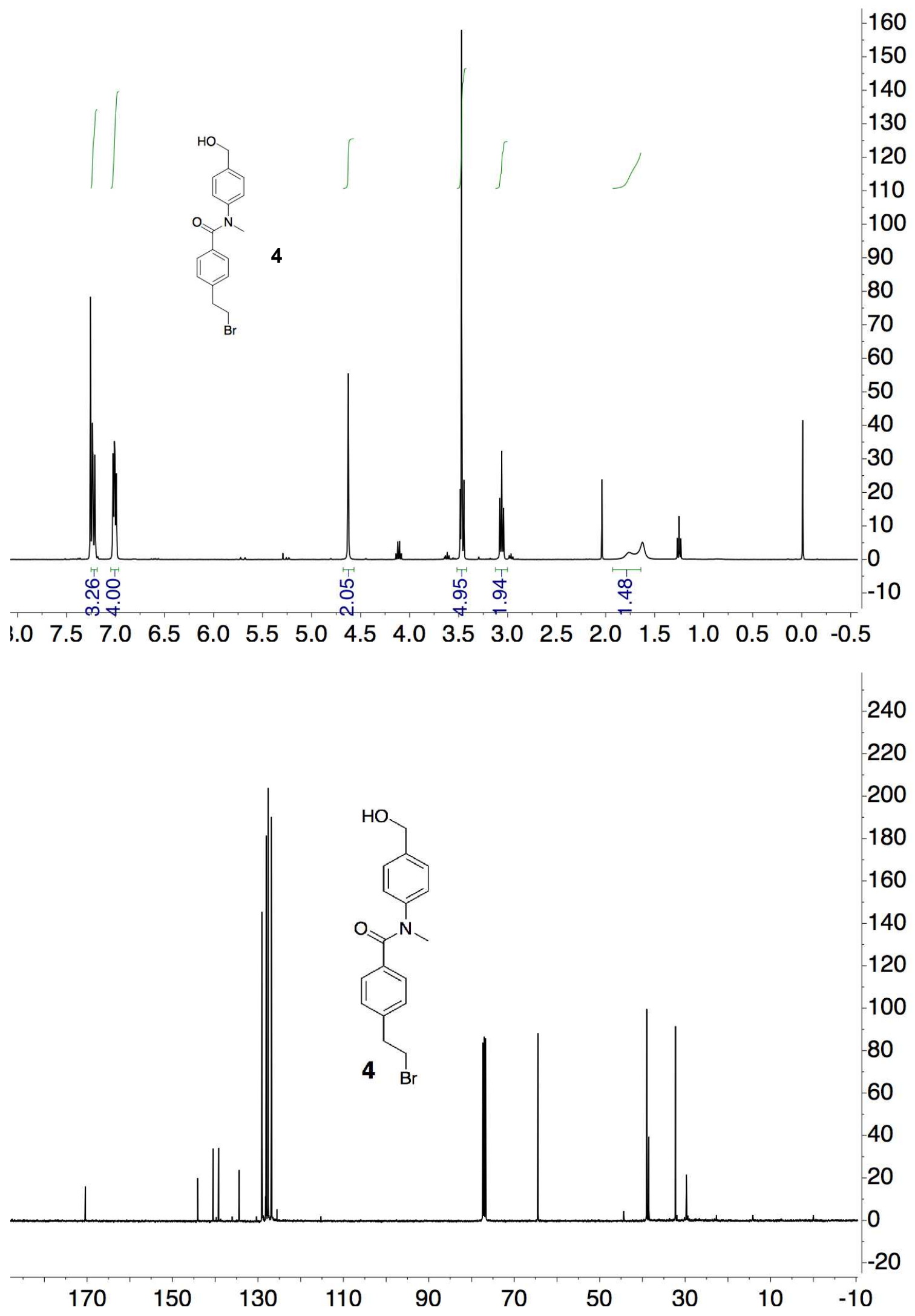

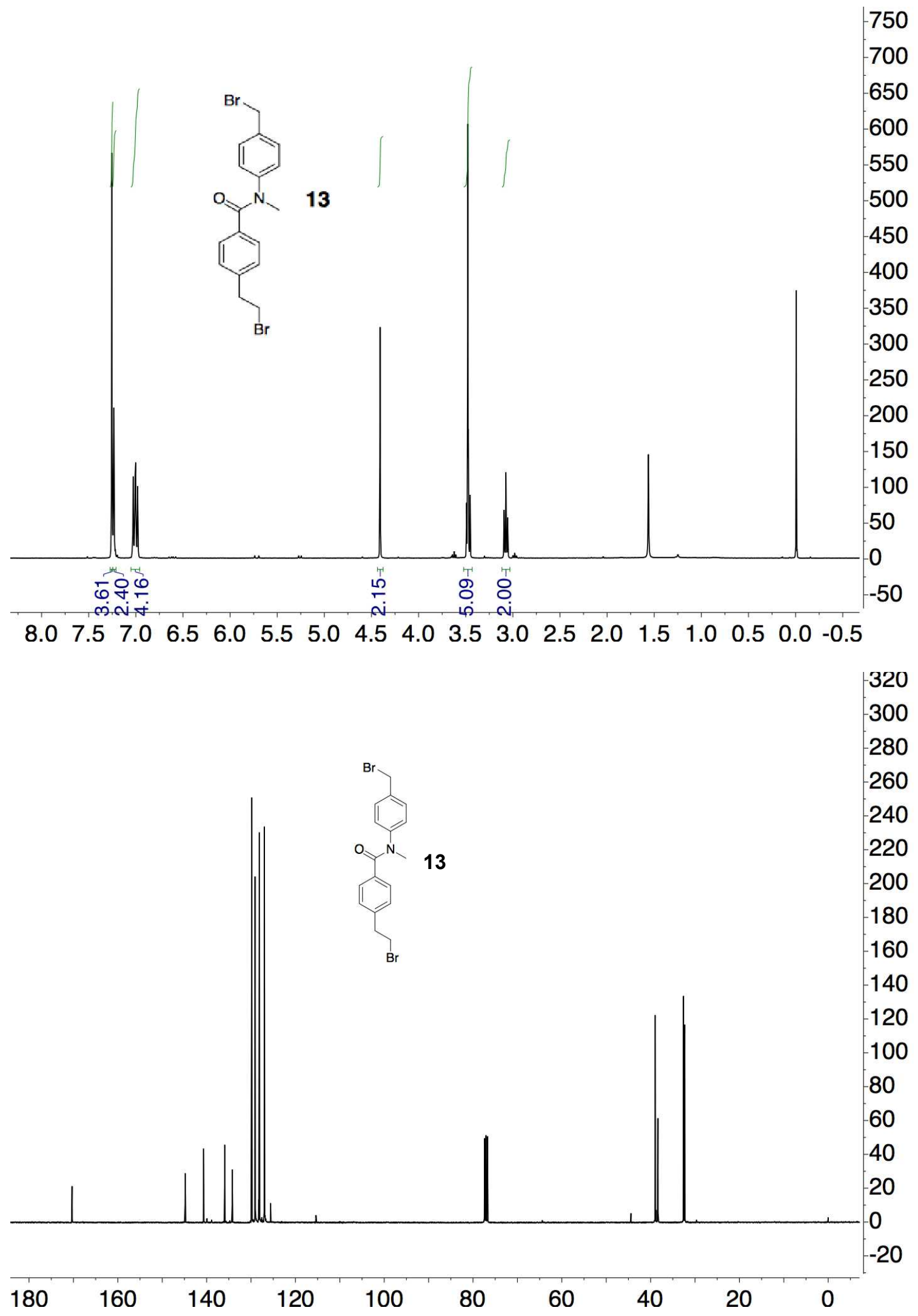


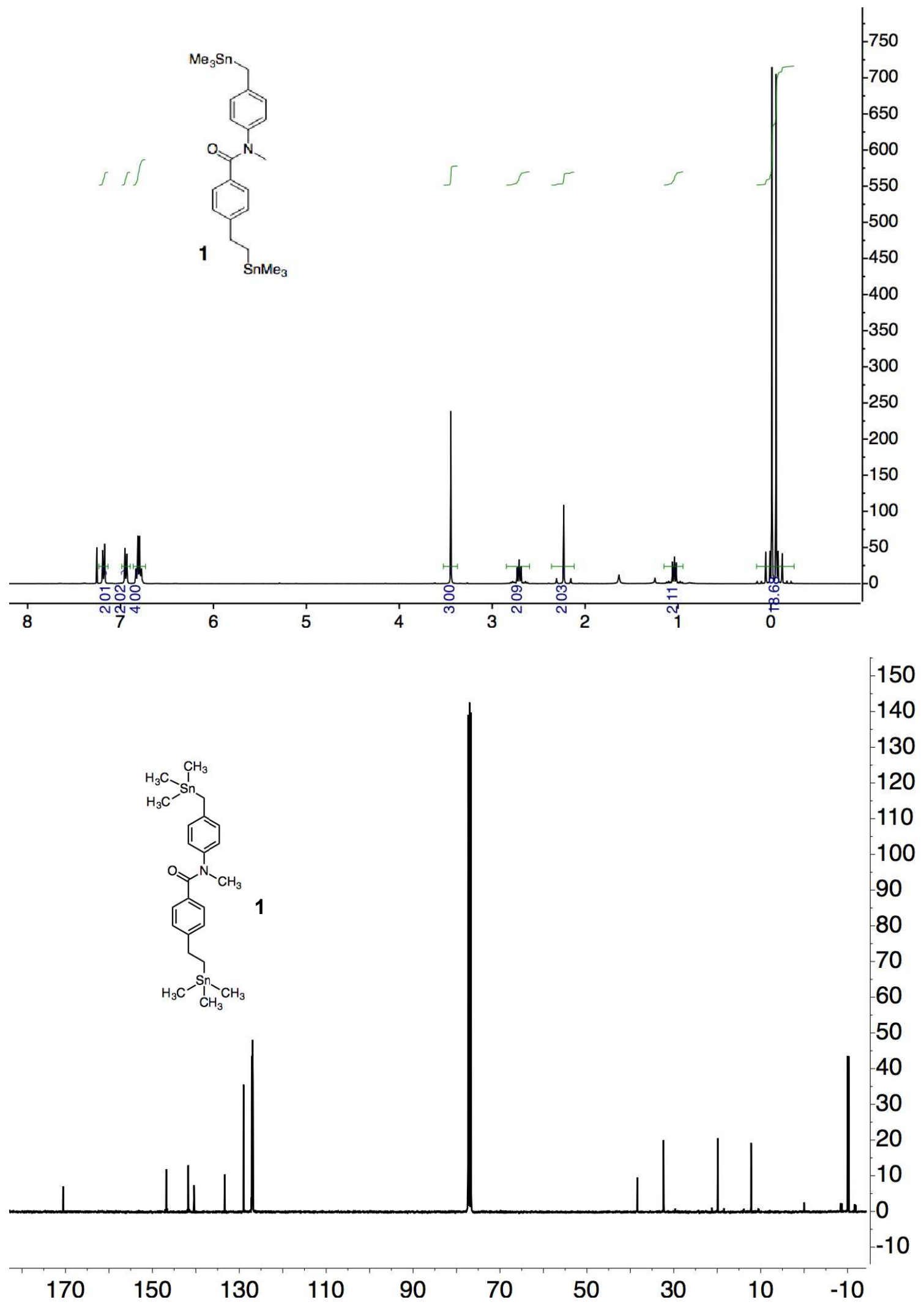



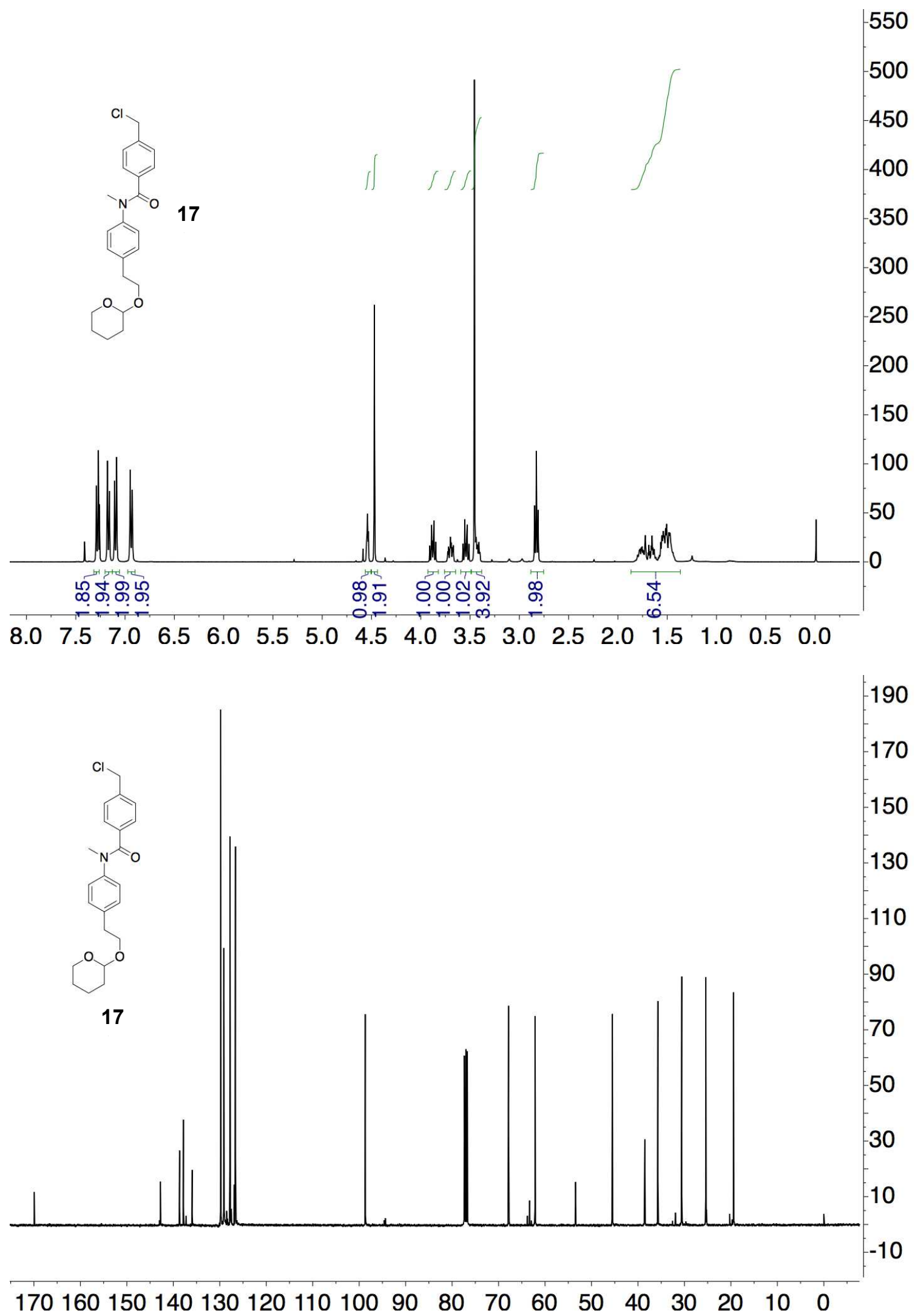


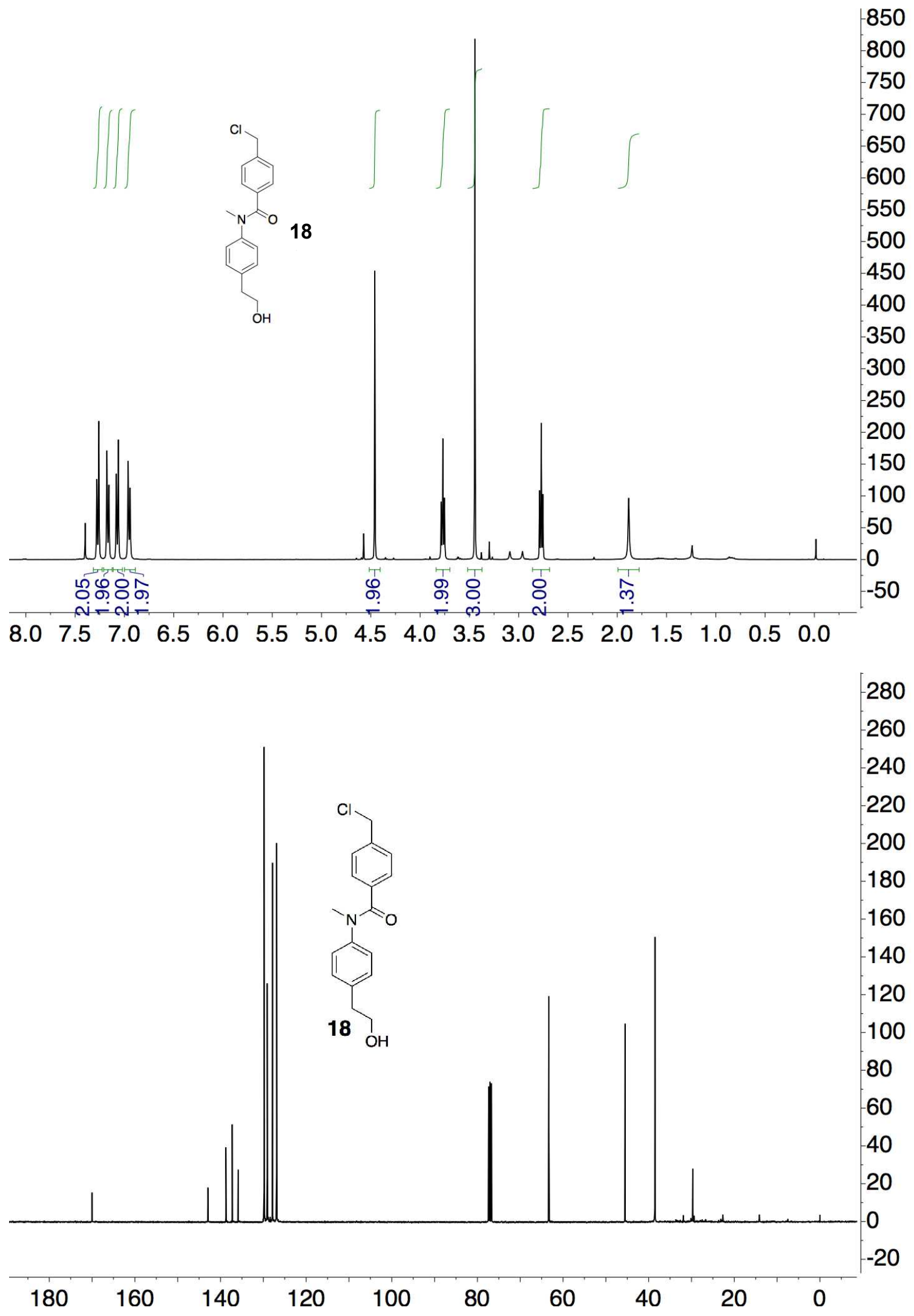



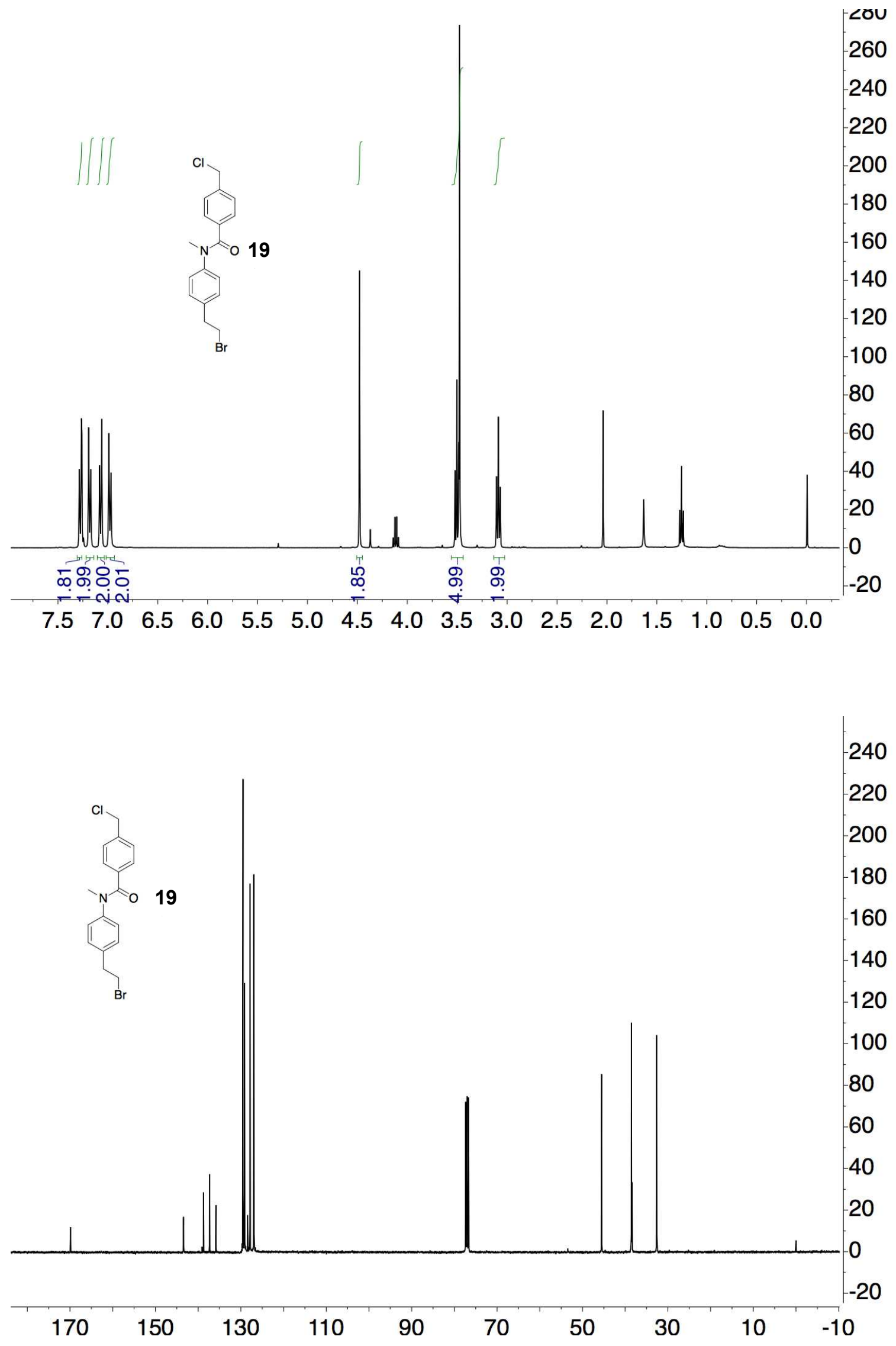

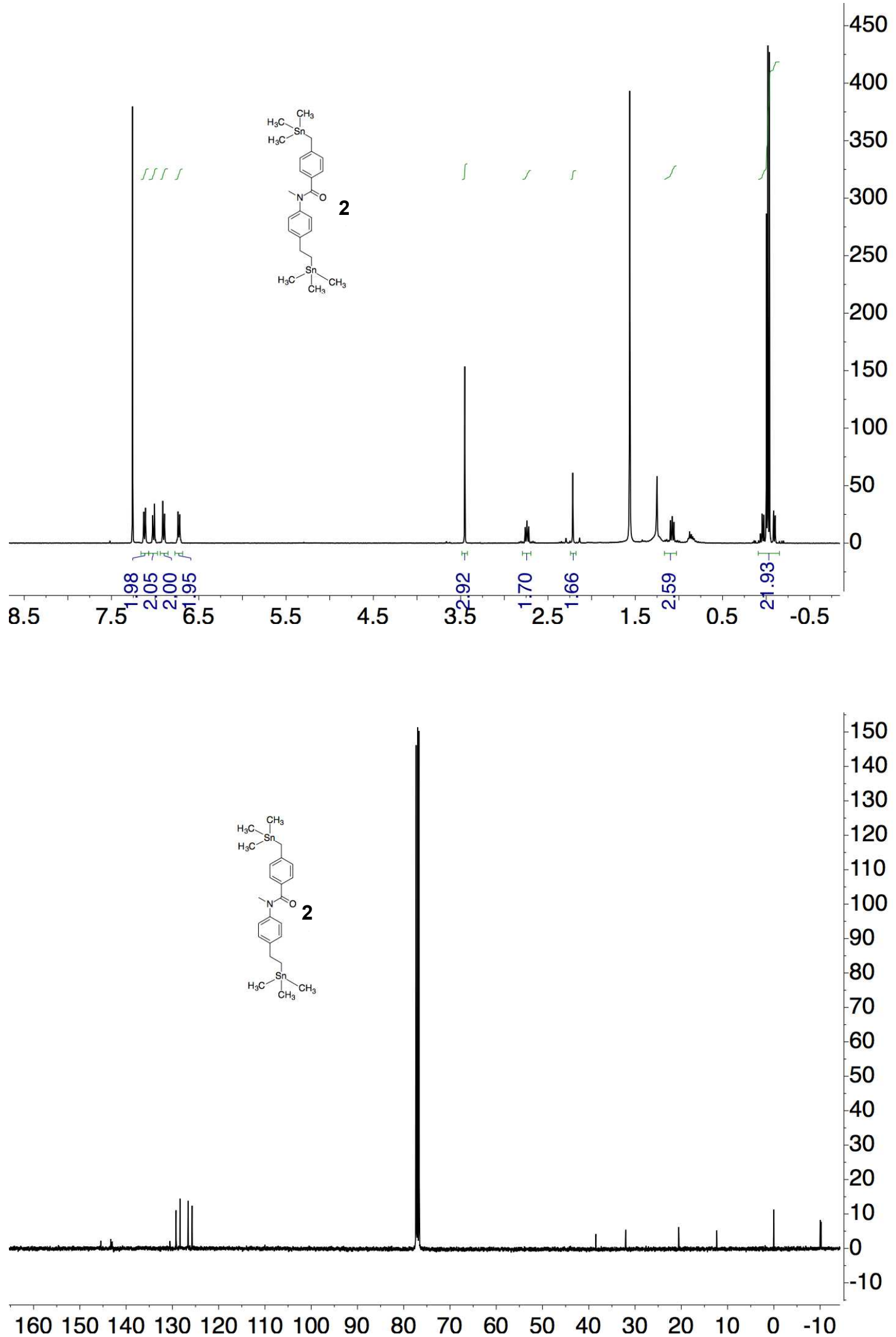